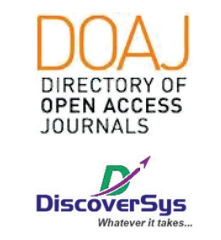

Published by DiscoverSys

\title{
The determinant factors for Quality of Life (QOL) among children with Acute Lymphoblastic Leukemia (ALL) after induction phase at Sanglah General Hospital, Bali, Indonesia
}

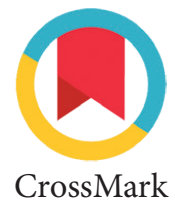

\author{
Made Suadnyani Pasek, Ketut Ariawati, ${ }^{*}$ Bagus Ngurah Putu Arhana, \\ I Gusti Lanang Sidiartha, I Gusti Ngurah Sanjaya Putra, \\ I Gusti Ngurah Made Suwarba
}

\section{ABSTRACT}

Background: The Quality of Life (QOL) of patients with acute lymphoblastic leukemia (ALL) is important to be examined. Some determinant factors of the QOL for ALL patients are age, gender, ethnicity, nutritional status, level of income of parents, educational level of parents, and risk groups. This study aims to determine the quality of life score among children with ALL after the induction phase of chemotherapy and to determine determinant factors that are associated with the quality of life of children with ALL.

Methods: An observational analytic study using a cross-sectional approach has been conducted among $38 \mathrm{ALL}$ patients to assess the $\mathrm{QOL}$ after the induction phase chemotherapy at Sanglah General Hospital. The independent sample $T$ test evaluated comparative values between independent factors. Multivariate analysis was assessed by the General
Linear Model ANCOVA. Data were analyzed using SPSS version 20 for Windows.

Results: Most of the respondents were age $>5$ years old ( $55.3 \%)$, followed by the male (55.3\%), well-nourished of nutritional status (55.3\%), low parents' educational status (55.3\%), a high income of parents (52.6\%), standard risk of stratification (52.6\%), and non-Balinese ethnicity (55.3\%). The mean score of Q0L was 79.37 \pm 21.64 . The results showed that male gender (95\% Cl: 2.35-16.04; $\mathrm{p}=0.010)$, high income of parents $(95 \%$ Cl: 3.17-22.05; $p=0.010)$, standard risk factors $(95 \% \mathrm{Cl}: 1.48-16.36$; $\mathrm{p}=0.020$ ) were significantly related to the $\mathrm{QOL}$ of children with ALL.

Conclusion: High-income parents, standard risk stratification, and male gender are determinant factors for higher Q0 $\mathrm{L}$ scores of children with ALL after the chemotherapy induction phase.

Keywords: ALL, Induction Phase, Determinant Factors, QOL.

Cite This Article: Pasek, M.S., Ariawati, K., Arhana, B.N.P., Sidiartha, I.G.L., Putra, I.G.N.S. Suwarba, I.G.N.M. 2020. The determinant factors for Quality of Life (QOL) among children with Acute Lymphoblastic Leukemia (ALL) after induction phase at Sanglah General Hospital, Bali, Indonesia. Intisari Sains Medis 11(2): 706-710. D0I: 10.15562/ism.v11i2.668

Department of Child Health, Medical School, Universitas Udayana, Sanglah General Hospital, Bali, Indonesia

${ }^{*}$ Correspondence to: Ketut Ariawati; Departement of Child Health, Medical School, Universitas Udayana, Sanglah General Hospital, Bali, Indonesia; ketutari_hemato@yahoo.com

Received: 2019-11-26 Accepted: 2020-06-23 Published: 2020-08-01

\section{INTRODUCTION}

Leukemia is a malignant disease of the bone marrow and blood characterized by the proliferation of white blood cells with the manifestation of abnormal cells in peripheral blood. ${ }^{1}$

Patients with acute leukemia will face intervention therapy, such as corticosteroids, chemotherapy, and an increased risk of infection. ${ }^{2}$ These will reduce the quality of life of these children. ${ }^{2}$ The study of the quality of life of ALL patients in the active phase of therapy, especially in the induction phase, is still few. ${ }^{3}$ The induction phase aims to kill most leukemia cells in the blood and bone marrow. ${ }^{1}$

Chemotherapy induction therapy requires long-term hospital care due to the hospital care has a detrimental effect on children and families. ${ }^{4}$ Stressors faced by children during a prolonged hospitalization such as a foreign environment, different habits, pain due to the treatment process, or the effects of care, separation from family members, and peers. ${ }^{3}$ The quality of life of ALL patients requires great attention. An examination of the quality of life in ALL patients is important, aiming for ALL patients and parents of patients to anticipate the events that occur during therapy. ${ }^{3}$ Quality of life examination can also help parents and health care workers to choose strategies to improve the quality of life for ALL patients. ${ }^{5}$ In addition to examining the quality of life, identification of determinants of quality of life in ALL patients is also important to know.

Some determinants of the quality of life for ALL patients are age, gender, ethnicity, nutritional status, level of income of parents, and risk groups. ${ }^{6}$ Research on the quality of life of pediatric ALL patients in the active phase of treatment showed that ALL patients in high-risk groups had a poorer quality of life compared to standard risk groups. ${ }^{3}$

Based on those mentioned above, this study aims to determine the determinant factors for Quality of Life (QOL) among children with Acute 
Lymphoblastic Leukemia (ALL) after induction phase at Sanglah General Hospital, Bali, Indonesia.

\section{METHODS}

This study was an observational study with a cross sectional design to determine the determinant factors of quality of life patient with ALL after completing the induction chemotherapy phase. This study was conducted from February 2017 September 2018 in the Pediatric Ward at Sanglah Hospital, Denpasar. Evaluation of quality of life score was obtained using the PedsQL 3.0 cancer module.

The subjects in this study were children aged 2 - 18 years with ALL, who fulfilled the inclusion and exclusion criteria. Inclusion criteria including ALL patients aged 2 to 13 years who were admitted to Sanglah General Hospital February 2017-September 2018, ALL patients after induction phase chemotherapy. Exclusion criteria, including ALL patients with critical conditions, suffering from congenital abnormalities, and intellectual disabilities, patients not willing to be respondents. Sampling is done by consecutive sampling until the number of samples was fulfilled.

\section{Table 1 Baseline characteristics of respondents}

\begin{tabular}{lc}
\hline Variable & Patients (N=38) \\
\hline Age, $\mathbf{n}(\%)$ & $21(55.3)$ \\
$>5$ years & $17(44.7)$ \\
$\quad<5$ years & \\
Gender, $\mathbf{n}(\%)$ & $17(44.7)$ \\
$\quad$ Female & $21(55.3)$ \\
$\quad$ Male & \\
Nutritional status, $\mathbf{n}(\%)$ & $21(55.3)$ \\
$\quad$ Well-nourished & $17(44.7)$ \\
Other than well-nourished & \\
Parents educational status, $\mathbf{n}(\%)$ & $17(44.7)$ \\
High & $21(55.3)$ \\
Low & \\
Parents income, $\mathbf{n}(\%)$ & $20(52.6)$ \\
High & $18(47.4)$ \\
Low & \\
Risk stratification, $\mathbf{n}(\%)$ & $18(47.4)$ \\
High risk & $20(52.6)$ \\
Standard risk & \\
Ethnicity, $\mathbf{n}(\%)$ & $17(44.7)$ \\
Balinese & $21(55.3)$ \\
Non-Balinese & $79.37 \pm 21.64$ \\
Average Score of QOL (Mean \pm SD) & \\
\hline
\end{tabular}

Subjects with ALL who fulfilled the eligibility criteria were given complete information regarding this study and asked for willingness to follow the study and sign the informed consent after getting and understand the information. Quality of life scores was taken using PedsQL 3.0 cancer module questionnaire and factors determinant of quality of life were measured. ${ }^{7}$ To test the normality of the study used the Shapiro-Wilk test. Descriptive analysis was performed to describe the characteristics of the subjects. Bivariate analysis was carried out with the Mann Whitney test. Multivariate analysis was carried out with the General Linear Model, ANCOVA. Data were analyzed by SPSS version 20 for Windows.

\section{RESULTS}

Table 1 shows the baseline characteristics of respondents during the study period. Most of the respondents were predominant by age $>5$ years (55.3\%), male gender (55.3\%), well-nourished of nutritional status (55.3\%), low parents' educational status (55.3\%), high parents income (52.6\%), standard risk stratification (52.6\%), non-Balinese ethnicity (55.3\%), and the average score of QOL ALL patients was $79.37 \pm 21.64$ (Table 1).

Bivariate analysis of determinant factors for the QOL of ALL patients was determine based on gender, parent's income, parent's educational status, and risk stratification. Mann-Whitney test of those determinants was showed in Table 2. The median (IQR) score of QOL among ALL patients tend to be higher in age $>5$ years old $(88.0(26))$, male gender (88.0 (14)), well-nourished nutritional status (87.7 (25)), and non-Balinese ethnicity (88.0 (22)) although not statistically significant ( $>0.05)$ (Table 2). However, there was a statistically significant difference in the median (IQR) QOL score of ALL patients in the parents' educational status $(\mathrm{p}=0.002)$, parents' income $(\mathrm{p}=0.000)$, and risk stratification ( $\mathrm{p}=0.045)$ (Table 2).

Multivariate analysis using General Linear Model ANCOVA by including determinant factors for quality of life scores was shown in Table 3. The table showed the determinant factors for quality of life were male gender $(B=9.19 ; 95 \%$ CI: 2.35 to $16.04, \mathrm{p}=0.010)$, high income of parents $(\mathrm{B}=$ 12.61; $95 \%$ CI: 3.17 to $22.05 ; \mathrm{p}=0.010$ ), standard risk factors $(\mathrm{B}=8.92 ; 95 \% \mathrm{CI}: 1.48$ to $16.36 ; \mathrm{p}=$ 0.020 ) related significantly to the better quality of life of children (Table 3).

\section{DISCUSSION}

Observational study with a cross sectional study on 38 children aged 2-18 years who underwent 
Table 2 The QOL of ALL patients according to age, gender, nutritional status, parents' educational level, parents' income, risk stratification, and ethnicity

\begin{tabular}{|c|c|c|}
\hline Variable & $\begin{array}{c}\text { QOL score } \\
\text { Median (IQR) }\end{array}$ & $\mathbf{p}$ \\
\hline \multicolumn{3}{|l|}{ Age } \\
\hline$>5$ years & $88.0(26)$ & 0.910 \\
\hline$<5$ years & $82.1(28)$ & \\
\hline \multicolumn{3}{|l|}{ Gender } \\
\hline Female & $72.9(29)$ & 0.110 \\
\hline Male & $88.0(14)$ & \\
\hline \multicolumn{3}{|l|}{ Nutritional status } \\
\hline Well-nourished & $87.7(25)$ & 0.330 \\
\hline Other than well-nourished & $82.0(25)$ & \\
\hline \multicolumn{3}{|l|}{ Parents educational level } \\
\hline High & $90.0(7)$ & 0.002 \\
\hline Low & $72.5(26)$ & \\
\hline \multicolumn{3}{|l|}{ Parents income } \\
\hline High & $89.4(5)$ & 0.000 \\
\hline Low & $67,0(24)$ & \\
\hline \multicolumn{3}{|l|}{ Risk stratification } \\
\hline High & $73.10(26)$ & 0.045 \\
\hline Standard & $87.85(19)$ & \\
\hline \multicolumn{3}{|l|}{ Ethnicity } \\
\hline Balinese & $82.2(27)$ & 0.510 \\
\hline Non-Balinese & $88.0(22)$ & \\
\hline
\end{tabular}

Table 3 Multivariate analysis of variables associated with the QOL score

\begin{tabular}{lcccc}
\hline Variable & B & $\mathbf{9 5 \%} \mathbf{C l}$ & $\mathbf{p}$ & R2 (\%) \\
\hline Male gender & 9.19 & $2.35-16.04$ & 0.010 & \\
High parents' educational level & 0.95 & $-9.12-11.04$ & 0.848 & \\
High parents' income & 12.61 & $3.17-22.05$ & 0.010 & \\
Standard risk stratification & 8.92 & $1.48-16.36$ & 0.020 & 56.5 \\
Age <5 years & -2.79 & $-6.68-6.32$ & 0.932 & \\
Bali ethnicity & -1.40 & $-7.80-4.99$ & 0.657 & \\
Well-nourished & 0.08 & $-7.21-7.37$ & 0.982 & \\
\hline
\end{tabular}

hospital care at Sanglah Hospital Denpasar starting in February 2017 until samples were fulfilled in September 2018, 2 children were excluded for not completing the induction phase. This study showed the quality of life of in the induction phase ALL children had an average of $79.37 \pm 21.64$. A previous study regarding the quality of life of ALL patients found a decrease in quality of life in ALL patients on treatment compared to patients who had undergone treatment for at least 2 years. ${ }^{5}$ Decreasing quality of life in the induction phase reflects a combination of the disease itself and the consequences of therapy. ${ }^{8}$ The value of the quality of life of children that we obtained in this study is also not much different from that reported in the study conducted by Martinez in 2008, regarding the quality of life in ALL patients in the induction phase. ${ }^{9}$ The study found that the average quality of life in the induction phase was $78.84 .{ }^{9}$

Gender is a determinant factor in some aspects of the quality of life of children with leukemia. Girls are reported to have better autonomous functions, while boys are reported to have a better quality of life in cognitive and emotional aspects. ${ }^{10}$ In this study, male patients increased the quality of life score of 9.19 better than female sex with a confidence range of 2.35 to 16.04 and $\mathrm{p}$-value $=0.010$. The results of this study are in line with the research on the quality of life of children with leukemia who are undergoing active treatment, found that girls have a poorer quality of life than men. ${ }^{11}$ Women in the general population are more likely to experience anxiety or depression and low self-esteem, which can ultimately reduce their quality of life. ${ }^{11}$

Lack of knowledge about cancer and the limitations of parents in obtaining information about the prognosis of cancer will result in anxiety for parents of patients. ${ }^{12}$ In this study, parents' educational factors were not related to the quality of life of patients. This is in line with the research conducted by Sitaresmi et al. in 2008 regarding the assessment of the quality of life of children with acute lymphoblastic leukemia in Indonesia. ${ }^{13}$ The results of this study found that the quality of life of children with high-educated parents was 73 and for children with low-educated parents a score was 68. The difference in results did not reach statistical significance based on the previous study. ${ }^{13}$ This is not in line with the results of research conducted by Ghodsbin et al. in 2014 regarding the effects of parental knowledge and education on the total score of quality of life. ${ }^{14}$ The study found a significant difference in the quality of life scores in children with parents with good knowledge compared to parents with less knowledge. ${ }^{14}$ The results of this different study may be due to the regular provision of communication, information, and education at the place where this research was conducted. Giving communication, information, and education to parents has an impact on increasing parents' knowledge about the disease suffered by their children, assisting children in dealing with illness and treatment, facing distress in children and reactions due to chemotherapy. ${ }^{15}$ In addition, it can also improve medication adherence, which will lead to a decrease in the incidence of recurrence and affect the quality of life of the child. ${ }^{16}$ Patients with ALL can be classified as high-risk and standard-risk. ${ }^{17}$ In general, patients at high-risk groups have a poorer 
quality of life than standard-risk groups. ${ }^{17}$ In this study, the score of the quality of life of the standard risk ALL patients was better 8.92 with a confidence range of 1.48 to 16.36 and p-value 0.020 . The results of this study are not very different from the results of research by Sung et al. in 2011 where scores for physical, psychosocial, and social aspects were worse for high-risk patients compared to standardrisk patients. ${ }^{11}$ Poorer quality of life in the high-risk group of patients occurs in all phases of treatment. In particular, pain, nausea, worry scores, physical appearance, and cognitive problems were significantly worse in high-risk patients. ${ }^{11}$ The results of this study are also in accordance with the results of a study by Magal-Vardi $\mathrm{O}$ et al., in 2004 that suggest risk stratification has a relationship with the quality of life. ${ }^{18}$ Children with the high-risk disease report a lower quality of life than children at moderate risk. ${ }^{18}$

Multivariate analysis of parent's income factors appears to affect the quality of life scores. The results of this study are in line with research by Sung $L$ et al. regarding the quality of life of ALL patients during the active treatment phase in Canada. ${ }^{11}$ The results of this study found that high family income significantly increased the quality of life scores of ALL patients similar with a previous study. ${ }^{11}$ The cost of treatment for cancer when the research was carried out was still covered by the government insurance, but to fulfill the daily necessities of life during treatment is very dependent on family income. Low family income, coupled with the inability to carry out work obligations because accompanying children to take medication, will cause stress and anxiety for parents that will affect the quality of life of children.

In the age factor, there was no statistically significant difference in the quality of life scores in preschool and school-age children. Still, it was found that the median quality of life scores in preschoolers was lower than school-age children. This is different from the results of research by Sidabutar et al. in 2012 regarding the description of the quality of life of school-age cancer patients, it was found that school-age children had a poorer quality of life than preschoolers. ${ }^{19}$ Theory argues that the economic conditions of parents strongly influence the quality of life of preschoolers. ${ }^{20}$ In theory, it is said that a low economic condition will hinder the development of preschoolers. ${ }^{20}$ A low economic situation results in adverse effects on social, emotional, and cognitive aspects, resulting in a decrease in quality of life. ${ }^{20}$ The differences in the results of this study with other studies may be because subjects with preschool-age mostly have parents with low income so that according to the theory mentioned, the child has a lower quality of life score than school-age children.

There was also no difference in the nutritional status factor in the quality of life scores between patients with well-nourished and other than wellnourished. Some studies show that nutritional status is a determinant factor in determining treatment outcomes and quality of life. ${ }^{21,22}$ Patients with acute lymphoblastic leukemia with poor nutrition are said to have a poorer quality of life than nonmalnutrition during chemotherapy induction. ${ }^{21}$ The difference in the results of this study was because the subjects of the research were comparing the quality of life scores of ALL patients with well-nourished with those with severe malnutrition status. In this study, ALL patients with severe malnutrition status were only 1 person and were included in other than the well-nourished group. The quality of life scores for the Balinese and non-Balinese did not show a significant difference, but the median quality of life scores in patients with the Balinese ethnicity was lower than the non-Balinese. Research conducted by Barakat et al. in 2010 found the same results, which found that the tribe did not affect the quality of life score. ${ }^{22}$ Other research has different things where the quality of life of children with ALL is influenced by several factors, including psychological factors, namely anxiety, and depression. ${ }^{22,23}$ Research on anxiety, depression, and behavioral changes in ALL patients suggests that ALL patients with particular ethnicity have worse symptoms of anxiety and depression. ${ }^{23}$ In this study, the median score for the Balinese ethnicity was lower than for the non-Balinese. This is probably due to the inability of parents to fulfill traditional "Banjar" obligations, causing stress in the family and decreasing the quality of life of children.

\section{CONCLUSION}

This study showed that the QOL of the induction phase ALL children had an average of 79.37 \pm 21.64 . This study proves that high-income parents, a standard risk, and male sex stratification as determinant factors of a higher quality of life scores in children with ALL after the chemotherapy induction phase.

\section{CONFLICT OF INTEREST}

The author declares there is no conflict of interest regarding the publication of the article.

\section{ETHICS CONSIDERATION}

This study has been approved by the Ethics Committee Faculty of Medicine Udayana University/Sanglah 
General Hospital with references number 264/ UN.14.2/KEP/2017.

\section{FUNDING}

The current study doesn't receive any specific grant from the government or any private sectors.

\section{AUTHOR CONTRIBUTION}

All of the authors are equally contribute to the study from the conceptual framework, data gathering, data analysis, until reporting the results of study through publication.

\section{REFERENCES}

1. Davis AS, Viera AJ, Mead MD. Leukemia: an overview for primary care. Am Fam Physician. 2014;89(9):731-738.

2. Hicks J, Bartholomew J, Ward-Smith P, Hutto CJ. Quality of life among childhood leukemia patients. J Pediatr Oncol Nurs. 2003;20(4):192-200.

3. van Litsenburg RR, Huisman J, Pieters R, Verhaak C, Kaspers GJ, Gemke RJ. Determinants of quality of life during induction therapy in pediatric acute lymphoblastic leukemia. Support Care Cancer. 2014;22(12):3235-3242.

4. Walter RB, Taylor LR, Gardner KM, Dorcy KS, Vaughn JE, Estey EH. Outpatient management following intensive induction or salvage chemotherapy for acute myeloid leukemia. Clin Adv Hematol Oncol. 2013;11(9):571-577.

5. Furlong W, Rae C, Feeny D, Gelber RD, Laverdiere C, Michon B, et al. Health-related quality of life among children with acute lymphoblastic leukemia. Pediatr Blood Cancer. 2012;59(4):717-724.

6. Dapueto JJ, Servente L, Francolino C, Hahn EA. Determinants of quality of life in patients with cancer. Cancer. 2005;103(5):1072-1081.

7. Varni JW, Burwinkle TM, Katz ER, Meeske K, Dickinson P. The PedsQL in pediatric cancer: reliability and validity of the Pediatric Quality of Life Inventory Generic Core Scales, Multidimensional Fatigue Scale, and Cancer Module. Cancer. 2002;94(7):2090-2106.

8. Bottomley A, Flechtner H, Efficace F, Vanvoorden V, Coens C, Therasse $\mathrm{P}$, et al. Health related quality of life outcomes in cancer clinical trials. Eur J Cancer. 2005;41(12):1697-1709.

9. Martinez DC, Villegas EJ. Quality of life in children with acute lymphoblastic leukemia during induction therapy with PedsQL cancer module. Bol Med Hosp Infant Mex. 2009;67(5):12-8

10. Landolt MA, Vollrath M, Niggli FK, Gnehm HE, Sennhauser FH. Health-related quality of life in children with newly diagnosed cancer: a one year follow-up study. Health Qual Life Outcomes. 2006;4:63. Published 2006 Sep 20.
11. Sung L, Yanofsky R, Klaassen RJ, Dix D, Pritchard S, Winick N, et al. Quality of life during active treatment for pediatric acute lymphoblastic leukemia. Int J Cancer. 2011;128(5):1213-1220.

12. Nair M, Paul LT, Latha PT, Parukkutty K. Parents' Knowledge and Attitude Regarding Their Child's Cancer and Effectiveness of Initial Disease Counseling in Pediatric Oncology Patients. Indian J Palliat Care. 2017;23(4):393-398.

13. Sitaresmi MN, Mostert S, Gundy CM, Sutaryo, Veerman AJ. Health-related quality of life assessment in Indonesian childhood acute lymphoblastic leukemia. Health Qual Life Outcomes. 2008;6:96.

14. Ghodsbin F, Asadi N, Javanmardi Fard S, Kamali M. Effect of education on quality of life of family caregivers of children with leukemia referred to the Oncology Clinic at Kerman's Afzali-Poor Hospital (Iran), 2012. Invest Educ Enferm. 2014;32(1):41-48.

15. Haugen MS, Landier W, Mandrell BN, Sullivan J, Schwartz C, Skeens MA, et al. Educating Families of Children Newly Diagnosed With Cancer. J Pediatr Oncol Nurs. 2016; 33(6):405-413.

16. Drzayich Antol D, Waldman Casebeer A, Khoury R, Michael T, Renda A, Hopson S, et al. The relationship between comorbidity medication adherence and health related quality of life among patients with cancer. J Patient Rep Outcomes. 2018;2:29.

17. Terwilliger T, Abdul-Hay M. Acute lymphoblastic leukemia: a comprehensive review and 2017 update. Blood Cancer J. 2017;7(6):e577. Published 2017 Jun 30.

18. Magal-Vardi O, Laor N, Toren A, Strauss L, Wolmer L, Bielorai B, et al. Psychiatric morbidity and quality of life in children with malignancies and their parents. J Nerv Ment Dis. 2004;192(12):872-875.

19. Sidabutar F, Anandari AR, Ezra, Karli I, Katagori Y, Wirawan H. Gambaran kualitas hidup pasien kanker pediatrik usia sekolah. IJCC. 2012;6(2):73-8.

20. Sandstrom H, Chaudry A. You have to choose your childcare to fit your work: childcare-decision making among low-income working family. JINS. 2012;17:120-32.

21. Hazarika NC, Dwivedi P. Nutritional Status and Induction Chemotherapy for Acute Lymphoblastic Leukemia. Indian Pediatr. 2015;52(5):379-380.

22. Barakat LP, Marmer PL, Schwartz LA. Quality of life of adolescents with cancer: family risks and resources. Health Qual Life Outcomes. 2010;8:63.

23. Myers RM, Balsamo L, Lu X, Devidas M, Hunger SP, Carroll WL, Winick NJ, et al. A prospective study of anXiety, depression, and behavioral changes in the first year after a diagnosis of childhood acute lymphoblastic leukemia: a report from the Children's Oncology Group. Cancer. 2014;120(9):1417-1425.

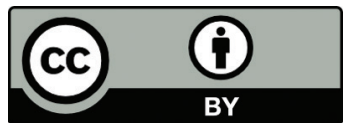

This work is licensed under a Creative Commons Attribution 